\title{
An anatomy of the cooling of the North Atlantic Ocean in the 1960s and 1970s
}

Article

Published Version

Open Access

Hodson, D. L. R., Robson, J. I. and Sutton, R. T. (2014) An anatomy of the cooling of the North Atlantic Ocean in the 1960s and 1970s. Journal of Climate, 27 (21). pp. 8229-8243. ISSN 1520-0442 doi: https://doi.org/10.1175/JCLI-D-1400301.1 Available at https://centaur.reading.ac.uk/37548/

It is advisable to refer to the publisher's version if you intend to cite from the work. See Guidance on citing.

Published version at: http://journals.ametsoc.org/doi/abs/10.1175/JCLI-D-14-00301.1

To link to this article DOI: http://dx.doi.org/10.1175/JCLI-D-14-00301.1

Publisher: American Meteorological Society

Publisher statement: (c) Copyright [date of publication] American Meteorological Society (AMS). Permission to use figures, tables, and brief excerpts from this work in scientific and educational works is hereby granted provided that the source is acknowledged. Any use of material in this work that is determined to be "fair use" under Section 107 of the U.S. Copyright Act September 2010 Page 2 or that satisfies the conditions specified in Section 108 of the U.S. Copyright Act (17 USC §108, as revised by P.L. 94-553) does not require the AMS's permission. Republication, systematic reproduction, posting in electronic form, such as on a web site or in a searchable database, or other uses of this material, except as exempted by the above statement, requires written permission or a license from the AMS. Additional details are provided in the AMS Copyright Policy, available on the AMS Web site located at (http://www.ametsoc.org/) or from the AMS at 617227-2425 or copyrights@ametsoc.org.

All outputs in CentAUR are protected by Intellectual Property Rights law, 
including copyright law. Copyright and IPR is retained by the creators or other copyright holders. Terms and conditions for use of this material are defined in the End User Agreement.

\section{www.reading.ac.uk/centaur}

\section{CentAUR}

Central Archive at the University of Reading

Reading's research outputs online 


\title{
${ }^{\circledR}$ An Anatomy of the Cooling of the North Atlantic Ocean in the 1960s and 1970s
}

\author{
DANIEL L. R. HODSON, JON I. ROBSON, AND ROWAN T. SUTTON \\ Department of Meteorology, University of Reading, Reading, United Kingdom
}

(Manuscript received 24 April 2014, in final form 30 July 2014)

\begin{abstract}
In the 1960s and early 1970s, sea surface temperatures in the North Atlantic Ocean cooled rapidly. There is still considerable uncertainty about the causes of this event, although various mechanisms have been proposed. In this observational study, it is demonstrated that the cooling proceeded in several distinct stages. Cool anomalies initially appeared in the mid-1960s in the Nordic Seas and Gulf Stream extension, before spreading to cover most of the subpolar gyre. Subsequently, cool anomalies spread into the tropical North Atlantic before retreating, in the late 1970s, back to the subpolar gyre. There is strong evidence that changes in atmospheric circulation, linked to a southward shift of the Atlantic ITCZ, played an important role in the event, particularly in the period 1972-76. Theories for the cooling event must account for its distinctive spacetime evolution. The authors' analysis suggests that the most likely drivers were 1) the "Great Salinity Anomaly" of the late 1960s; 2) an earlier warming of the subpolar North Atlantic, which may have led to a slowdown in the Atlantic meridional overturning circulation; and 3) an increase in anthropogenic sulfur dioxide emissions. Determining the relative importance of these factors is a key area for future work.
\end{abstract}

\section{Introduction}

During the twentieth century, sea surface temperatures (SSTs) in the North Atlantic exhibited substantial decadal-scale variability. In particular, SSTs in the North Atlantic warmed rapidly between 1920 and 1940 and cooled rapidly between 1960 and 1980 (Fig. 1). These observed changes in SST have been linked, in both observational and modeling studies, to substantial changes in climate. For example, there is evidence of links to changes in rainfall over the Sahel (Folland et al. 1986; Hoerling et al. 2006; Zhang and Delworth 2006) and Nordeste Brazil region (Uvo et al. 1998; Folland et al. 2001; Zhou and Lau 2001; Knight et al. 2006), summertime North American climate (McManus et al. 2004; Sutton and Hodson 2005; Sutton and Hodson 2007), and Atlantic hurricane genesis (Shapiro and Goldenberg 1998; Enfield et al. 2001; Goldenberg et al. 2001). Baines and Folland (2007) demonstrated that

¿ Denotes Open Access content.

Corresponding author address: Daniel L. R. Hodson, Department of Meteorology, University of Reading, Earley Gate, P.O. Box 243, Reading RG6 6BB, United Kingdom.

E-mail: d.l.r.hodson@reading.ac.uk substantial changes in climate in many of these regions occurred rapidly and in concert in the decade centered on the late 1960s - the period when the North Atlantic cooled most rapidly (Fig. 1). This cooling was highlighted by Thompson et al. (2010), who demonstrated that a rapid drop in Northern Hemisphere temperatures of $\sim 0.3 \mathrm{~K}$ occurred between 1968 and 1972, with a warming in the Southern Hemisphere, in contrast to more recent interhemispheric temperature trends (Friedman et al. 2013). The largest cooling occurs in the North Atlantic subpolar gyre. The cooling in this region occurred at the same time as a rapid drop in near-surface salinity, the first documented "Great Salinity Anomaly" (GSA) (Dickson et al. 1988; Belkin et al. 1998).

There is as yet no consensus on the causes of the North Atlantic cooling event. Several potential explanations exist in the literature. One possibility is the GSA, which is thought to have been caused by an increase in the flow of cold, fresh water from Arctic, possibly triggered by preceding wind anomalies (Dickson et al. 1988; Belkin et al. 1998). Another possibility is a slowdown in the Atlantic meridional overturning circulation (AMOC). The observed pattern of SST cooling (Fig. 1) is similar to that associated with a reduction of the AMOC in coupled climate models (Vellinga and Wood 2002; Dong and Sutton 2007; Knight et al. 2006; Hodson and Sutton 2012). Furthermore, Robson et al. (2014) recently demonstrated that in one decadal prediction system 


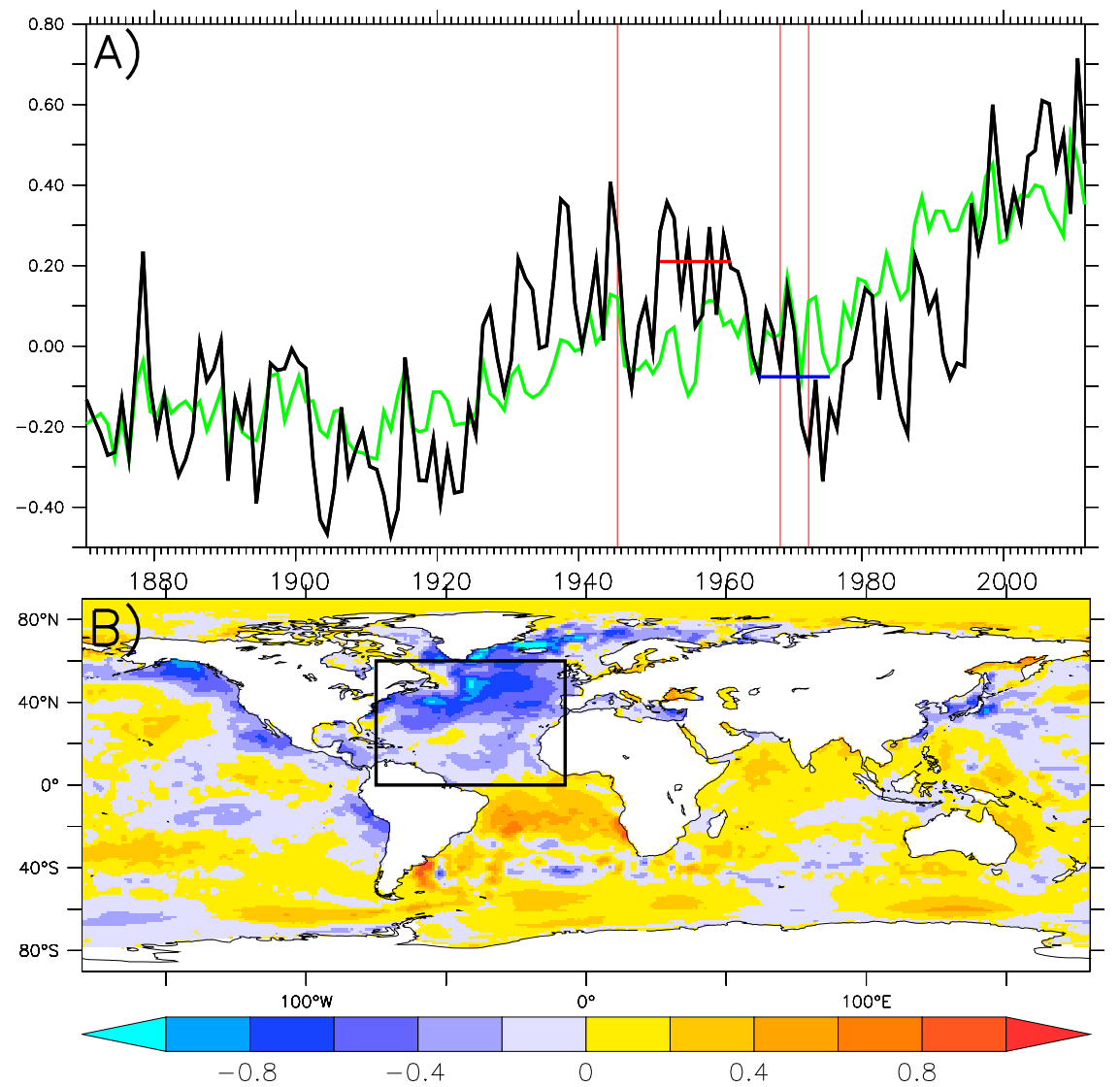

FIG. 1. (a) Atlantic multidecadal oscillation (AMO): area-weighted mean annual-mean SSTs (HadISST) over the North Atlantic Ocean $\left[0^{\circ}-60^{\circ} \mathrm{N}, 7.5^{\circ}-75^{\circ} \mathrm{W}\right.$; black box in (b) $]$ shown in black and for all area outside that shown in green. Vertical red lines denote (i) 1945 cooling attributed to instrumental changes (Thompson et al. 2008) and (ii) the period of the 1970s cooling documented in Thompson et al. (2010). Horizontal red and blue lines indicate periods used to form the composite [in (b)]. (b) The mean of annual-mean SSTs (1965-75) minus the mean of annual-mean SSTs (1951-61).

initialization of the AMOC plays a key role in the skill of predictions of this cooling event.

This period also saw considerable variation in natural and anthropogenic forcings (Fig. 2). There was a marked increase in volcanic activity, beginning with the eruption of Agung in 1963/64. Stratospheric aerosols from such large eruptions have a significant cooling effect on global SSTs, via a reduction of downwelling surface shortwave radiation. This direct influence is thought to last no more than 1-2 yr (Robock and Mao 1995). In addition, however, modeling studies show that tropical stratospheric aerosols lead to a warming of the tropical lower stratosphere and a resulting intensification of the Northern Hemisphere polar vortex (Graft et al. 1993; Zanchettin et al. 2012). Such changes in atmospheric circulation might have influenced freshwater transports from the Arctic Ocean (Condron et al. 2009). Volcanic forcing may also influence the AMOC via a range of mechanisms (Ottera et al. 2010; Iwi et al. 2012; Swingedouw et al. 2013), which could be relevant to the cooling of the North Atlantic in the 1960s.

There was also a decrease in solar irradiance between the late 1950s and the late 1960s (Fig. 2). While the absolute magnitude of these changes was small, some modeling studies suggest that the impact of such changes may be regionally amplified by various mechanisms within the climate system (Haigh 1999; Meehl et al. 2009; Ineson et al. 2011; Gray et al. 2009; Gray et al. 2010). Therefore, it is possible that solar forcing might have contributed to the observed cooling event.

Finally, the significant rise in anthropogenic sulfur dioxide $\left(\mathrm{SO}_{2}\right)$ emissions during the latter half of the twentieth century (Fig. 2) is likely to have had a significant cooling impact. Once in the atmosphere, $\mathrm{SO}_{2}$ oxidizes to $\mathrm{SO}_{4}$ and acts to reduce downwelling shortwave radiation, both via direct scattering and indirectly by increasing cloud reflectivity and lifetimes (Haywood and Boucher 2000). Emissions from the United States 

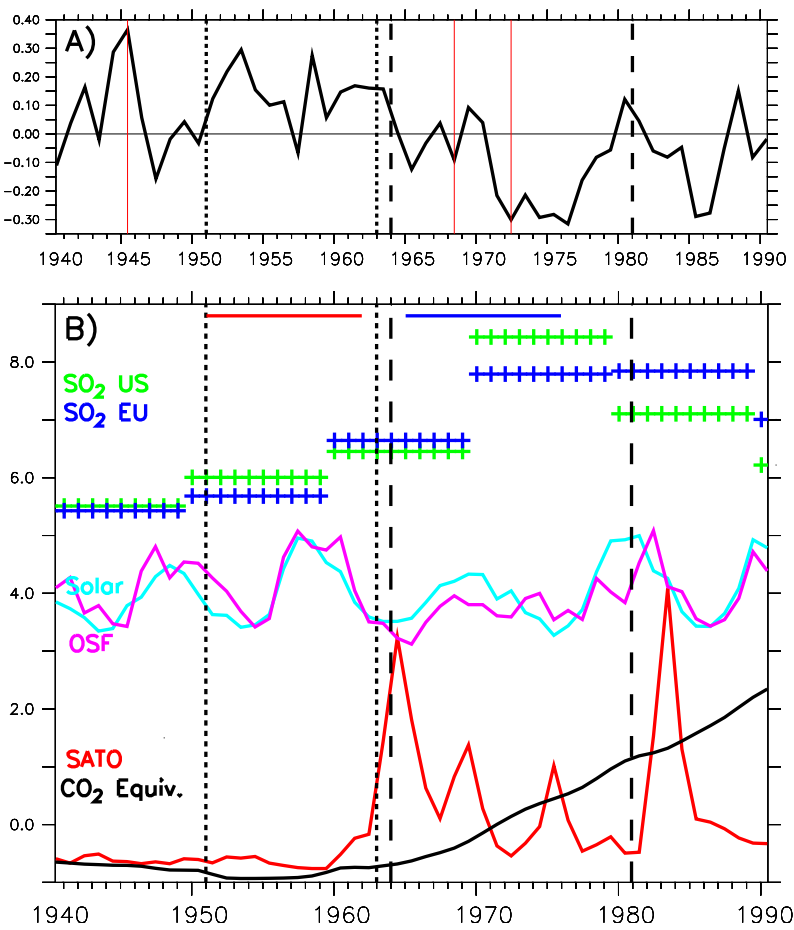

FIG. 2. (a) AMO (October-June mean, unit: K) (see Fig. 1). (b) External forcing time series for the twentieth century. Upper green and blue lines show the total sulfur dioxide emissions from all sectors: area-weighted mean over the U.S. region (green: $65^{\circ}-25^{\circ}-$ $50^{\circ} \mathrm{N}, 160^{\circ} \mathrm{W}$ ) and European Union region (blue: $25^{\circ}-70^{\circ} \mathrm{N}, 20^{\circ}-$ $70^{\circ} \mathrm{E}$ ), respectively, computed from historical RCP estimates (https://tntcat.iiasa.ac.at:8743/RcpDb/; Smith et al. 2011). The middle light-blue line shows the total solar irradiance (TSI): forcing used for CMIP5 [from Lean (2000) with background from Wang et al. (2005)]. This is overplotted with an estimate of the open solar flux (magenta, Lockwood et al. 2009; Vieira and Solanki 2010). The lower red lines shows the global mean stratospheric aerosol optical thickness due to volcanic emissions (http://data.giss.nasa.gov/ modelforce/strataer/; Sato et al. 1993). The lower black line shows $\mathrm{CO}_{2}$ equivalence concentrations, aggregate of all anthropogenic forcings (greenhouse gases plus aerosols) from the RCP database (Meinshausen et al. 2011). All indices have been standardized to have unit variance and offset from zero to aid visual comparison. Vertical dotted lines indicate the warm Atlantic reference period (1951-62) and the vertical dashed lines indicate the cold Atlantic period under analysis (1964-80).

peaked around 1970, whereas European emissions peaked sometime between 1970 and 1980 (Fig. 2) (Smith et al. 2004). Analyses of observations (Mann and Emanuel 2006) suggest that anthropogenic tropospheric aerosols offset twentieth-century anthropogenic warming in the tropical Atlantic to some degree. Unlike greenhouse gases, which are generally well mixed in the atmosphere, the short atmospheric residence time of tropospheric sulfate aerosols means that they are inhomogeneously distributed, suggesting that regional cooling responses might be expected. Several studies using atmosphere models coupled to ocean mixed layer models have demonstrated that sulfate aerosols can cool the SSTs in the Atlantic (Williams et al. 2001; Rotstayn and Lohmann 2002; Ming and Ramaswamy 2009). Booth et al. (2012) argued that coupled models with aerosol schemes that include the indirect effect of sulfate aerosol on cloud reflectivity can successfully reproduce the observed decadal variability of North Atlantic SSTs, including the cooling in the 1960s. However, the observed spatial pattern of Atlantic cooling is somewhat different to that found in the ensemble mean response of simulations of Booth et al. (2012) and the observed subsurface ocean temperature changes are markedly different to those simulated. Hence, the interpretation of Booth et al. (2012) is currently a matter of debate (Zhang et al. 2013).

Baines and Folland (2007), in their analysis of the late 1960s climate shift, concluded that climatic changes at the time most likely arose as a consequence of either internal ocean variability (e.g., related to the AMOC) or changes in sulfate aerosol forcing; they concluded that other factors, including greenhouse gas forcing, solar irradiance, ozone, and desertification, were unlikely to have played a major role. However, it is clear that significant uncertainties remain. In view of the wider importance (e.g., for climate change adaptation) of understanding climatic changes on decadal time scales, it is important to seek further evidence that may help to identify the causes of the cooling of the North Atlantic in the 1960s and of the associated changes in climate.

The approach taken in this observational study is to focus in detail on the evolution of sea surface temperatures, and related variables. By analyzing the space-time evolution of the cooling event we seek evidence that may favor some mechanisms and discount, or render less likely, others. The paper is set out as follows: Section 2 outlines the datasets used in the analysis. Section 3 describes the space-time evolution of SSTs and other variables. The interpretation of this evolution is discussed in section 4 , and conclusions are in section 5 .

\section{Data and methods}

In this section we briefly detail the datasets used in this analysis. Sea surface temperatures were extracted from the Hadley Centre Sea Ice and Sea Surface Temperature dataset (HadISST), the Met Office (UKMO) Hadley Centre's (HC) reduced-space optimal interpolation product (Rayner et al. 2003). Ocean salinity and subsurface ocean temperatures were extracted from the UKMO HC's EN3 objective ocean analysis (Ingleby and Huddleston 2007). Mean sea level pressures (MSLPs) were extracted from the second Hadley Centre Sea Level Pressure dataset (HadSLP2) (Allan and Ansell 2006). All three datasets were downloaded from the Met Office (http://www.metoffice.gov.uk/hadobs/). The NAO index 
(used in Fig. 6) was downloaded from the Climatic Research Unit (CRU) (http://www.cru.uea.ac.uk/cru/data/ nao/; Jones et al. 1997). The Global Precipitation Climatology Centre (GPCC) monthly precipitation (Schneider et al. 2014; Becker et al. 2013) dataset was downloaded from the National Oceanic and Atmospheric Administration (http://www.esrl.noaa.gov/psd/data).

Phase 5 of the Coupled Model Intercomparison Project (CMIP5) historical forcings $\left(\mathrm{CO}_{2}\right.$ equivalent and anthropogenic $\mathrm{SO}_{2}$ emissions) were downloaded from the representative concentration pathway (RCP) database (version 2.0.5). A historical reconstruction of the total solar irradiance (from http://solarisheppa.geomar. de/solarisheppa/cmip5; Lean 2000) and the open solar flux (from http://www.eiscat.rl.ac.uk/Members/mike/ Open \%20solar\%20flux\%20data/openflux1675to2010. txt; Lockwood et al. 2009) were obtained online. The historical optical thickness changes due to stratospheric aerosols were obtained online (from http://data.giss. nasa.gov/modelforce/strataer/; Sato et al. 1993).

In the subsequent analyses we concentrate on two seasons: an extended winter season, October-June, and a summer season, July-September. We chose these seasons because preliminary analyses showed that subseasonal variations within October-June were small compared to those between October-June and JulySeptember. We construct composite differences by subtracting the mean of successive 5 -yr periods in the interval 1964-80 from the mean of the reference period, 1951-62. We chose the reference period as it immediately precedes the cooling, is representative of the extended 1930-60 warm period (Fig. 1a) and avoids the known 1945 instrumental cold bias (Thompson et al. 2008). In all composite difference plots a significance difference is defined as one that lies outside the $95 \%$ confidence level $(p<0.05)$ according to a two-tailed $t$ test. We allow for unequal variances within the two periods in this $t$ test: this results in a reduction in the effective number of degrees of freedom in some places, between $15(N=12+5-2)$ and 4.5 . We tested the robustness of the results by examining the results when using four degrees of freedom everywhere. The key features of Figs. 3 and 4 were unchanged by this. We therefore believe them to be robust patterns.

\section{Evolution of sea surface temperature and mean sea level pressure}

In this section, we describe the evolution of sea surface temperatures and mean sea level pressure (Figs. 3-6) through the cooling period. The North Atlantic cooling began in the early 1960s and continued through the middle to late 1970s (Fig. 1). In terms of the basin mean temperature, the cooling occurred in two stages: an initial cooling from 1962 to 1965 , followed by a second cooling between 1970 and 1975. The latter event was analyzed and discussed by Thompson et al. (2010). While the prominent cooling in 1945 has been attributed to instrumentation changes (Thompson et al. 2008), there is no evidence to suggest that these later events are measurement artifacts. The pattern of the cooling anomaly (Fig. 1b) extends throughout the North Atlantic, with a maximum in the extratropics. Cool anomalies are also seen in the northeast and northwest Pacific.

This decadal pattern of Atlantic cooling is well known, but the details of its development are obscured by decadal averaging. Therefore, we now examine successive 5-yr averages to elucidate the stages involved. As discussed in the previous section, we split the analysis into two seasons: an extended winter season, OctoberJune (ONDJFMAMJ), and a summer season, JulySeptember (JAS). We examine 5-yr anomalies of SST and MSLP relative to the 1951-62 reference period. Results are shown in Figs. 3 and 4. The results for summer are generally noisier than for the extended winter season, which may be a consequence of the shallower summer mixed layer. [It does not appear to be simply a result of averaging over more months (not shown).]

\section{a. $1964-68$}

The initial cooling in both seasons is largely confined to the Nordic Seas and the region of the Gulf Stream Extension. The anomaly in the Nordic Seas is larger in magnitude and extent in July-September $(-0.8 \mathrm{~K}$ over $65^{\circ}-75^{\circ} \mathrm{N}, 20^{\circ} \mathrm{E}-20^{\circ} \mathrm{W}$ ) compared to October-June $(-0.6 \mathrm{~K})$. There are no notable atmospheric circulation anomalies during this period, aside from a small low MSLP anomaly over the Arctic in October-June.

\section{b. $1968-72$}

As the cooling progresses further, cool anomalies extend to cover much of the subpolar gyre (SPG) and northern midlatitudes. A larger area of the Atlantic shows significant cool anomalies during October-June than July-September; however, the SPG anomalies are of greater magnitude in July-September (JAS) $(-0.9 \mathrm{~K}$, October-June: $-0.5 \mathrm{~K}$ over $\left.54^{\circ}-63^{\circ} \mathrm{N}, 17^{\circ}-46^{\circ} \mathrm{W}\right)$. There is a hint of low MSLP anomalies over North Africa in both seasons, but the most prominent evidence of circulation anomalies is a significant, if weak, anticyclonic anomaly in July-September, which extends over northern Europe and into Asia.

\section{c. $1972-76$}

The cool anomalies reach their maximum magnitude and spatial extent during this period, in both seasons. 

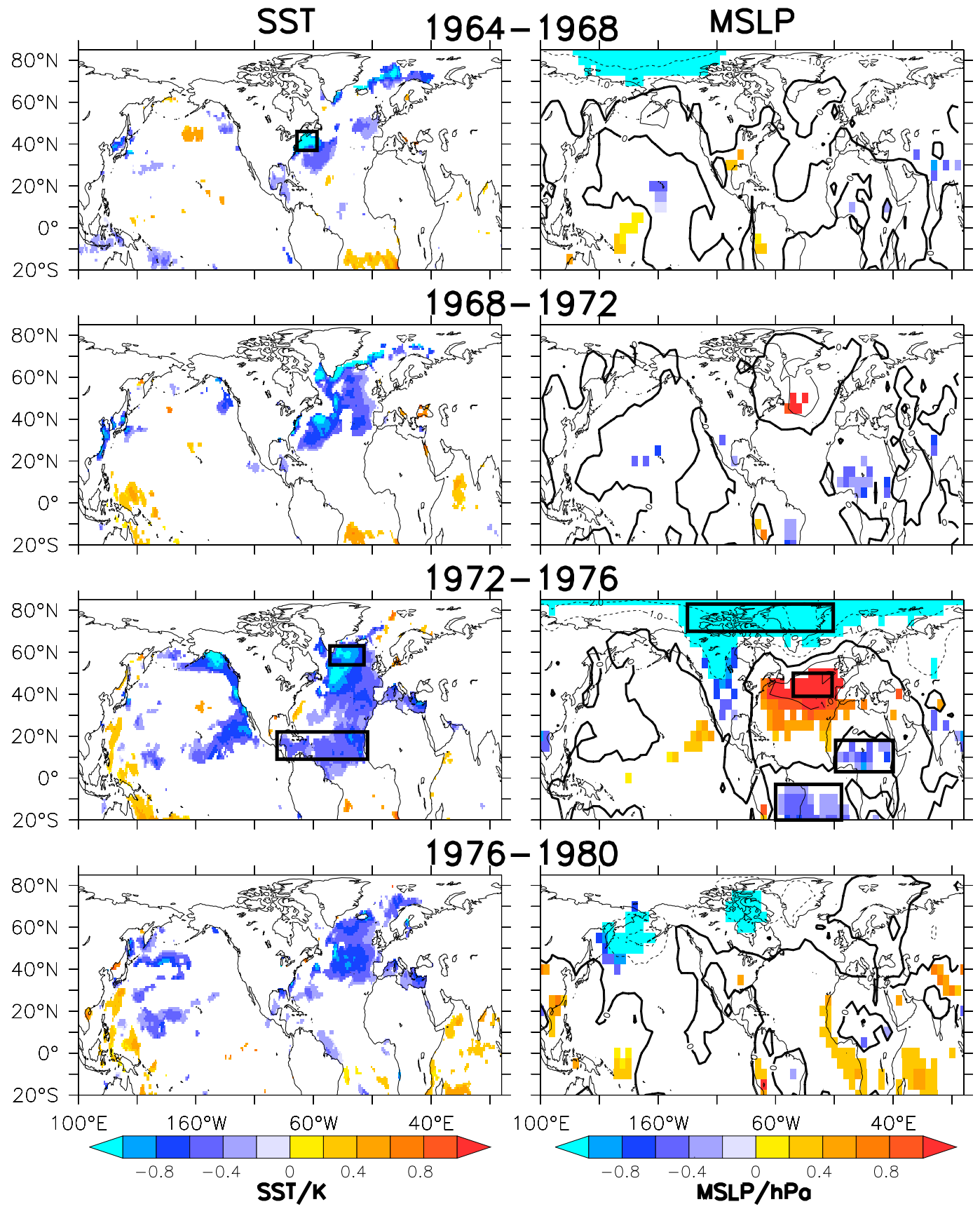

FIG. 3. (left) Means of observed sea surface temperatures (from HadISST) for four successive periods: 1964-68, 1968-72, 1972-76, and 1976-80, minus the 1951-62 mean, for the mean of October-June (unit: K). Shaded (nonwhite) areas show significant differences $(p<0.05$ ). (right) As in (left), but for mean sea level pressure (from HadSLP, unit: $\mathrm{hPa}$ ). Boxes show regions defined for indices in Figs. 5 and 6.

In October-June, cool anomalies extend from the SPG $\left(54^{\circ}-63^{\circ} \mathrm{N}, 17^{\circ}-46^{\circ} \mathrm{W}\right)$, where they are maximum $(-0.8 \mathrm{~K})$, into the tropical North Atlantic (TNA) $\left(9^{\circ}-22^{\circ} \mathrm{N}, 14^{\circ}-91^{\circ} \mathrm{W} ;-0.5 \mathrm{~K}\right)$, and as far east as the Mediterranean $(-0.5 \mathrm{~K})$. The western part of the subtropical North Atlantic does not show a significant cooling, resulting in a tripole (or horseshoe) pattern. Interestingly, this pattern is partly mirrored in the similar, but weaker, cooling pattern seen in the Pacific in October-June during this period. The pattern of cool anomalies is less extensive in July-September, but the largest anomalies are again seen in the SPG $(-1.1 \mathrm{~K})$ 

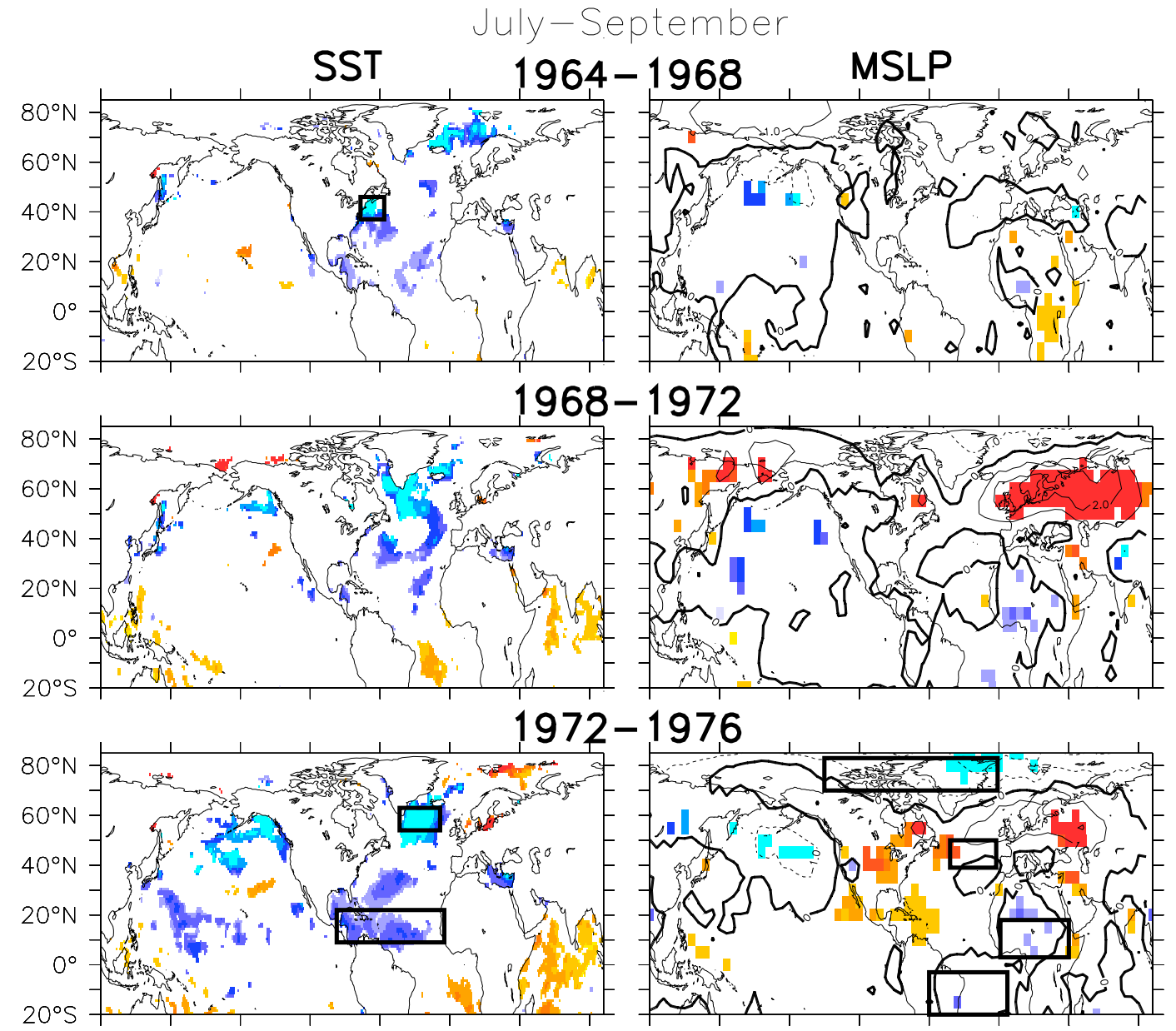

\section{$-1976$}
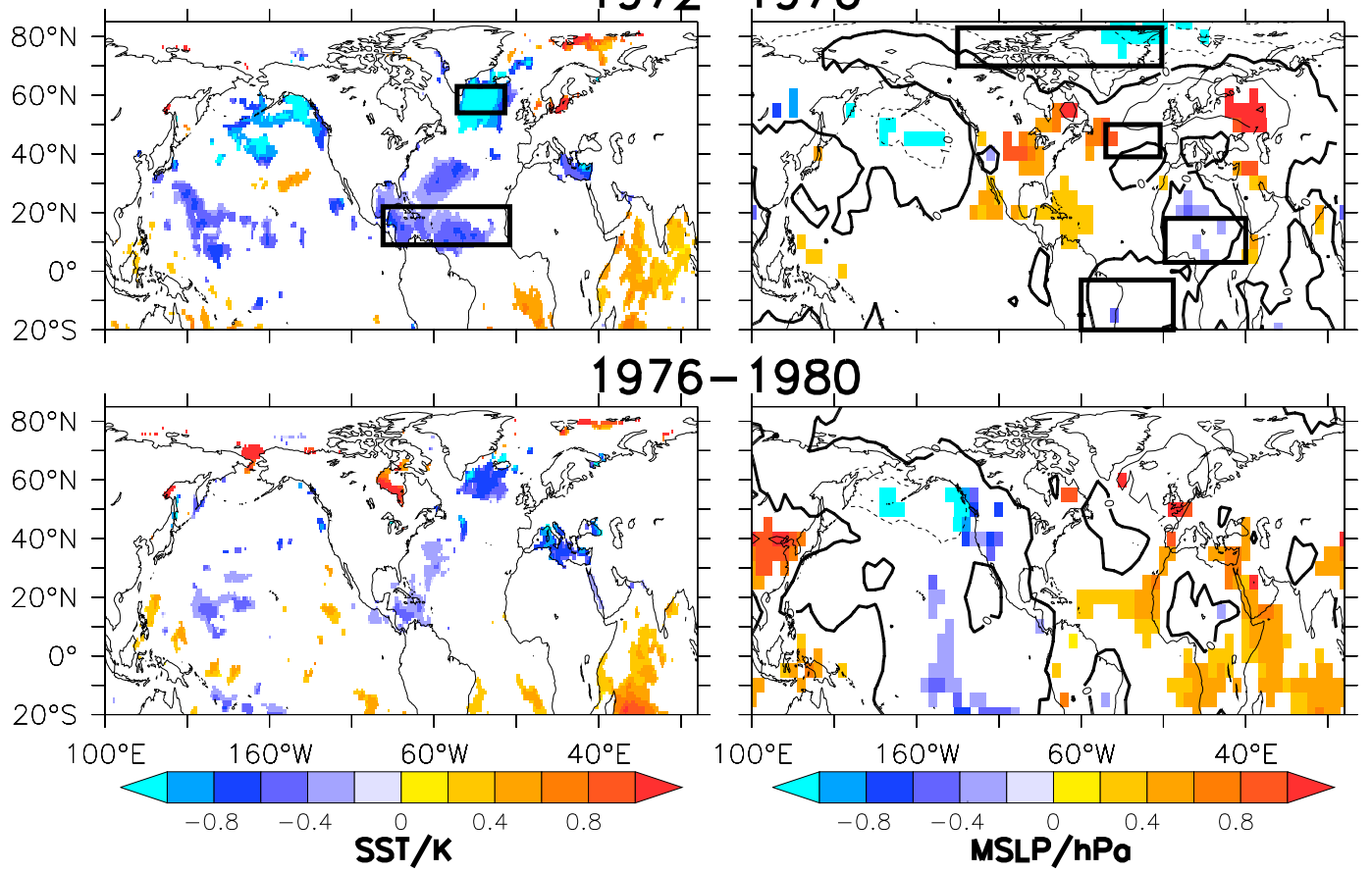

\section{$-1980$}

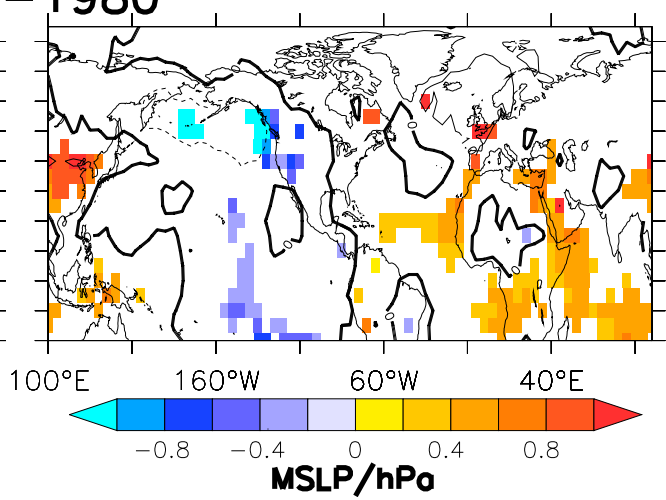

FIG. 4. As in Fig. 3, but for July-September.

together with significant cool anomalies in the TNA region.

There is also evidence of significant anomalies in atmospheric circulation during this period. The pattern of MSLP anomalies for October-June projects on the positive phase of the North Atlantic Oscillation (NAO): the anomalous pressure difference between the two lobes is nearly $4 \mathrm{hPa}$. Significant low pressure anomalies are also seen over western Africa and eastern South America, extending over the tropical Atlantic. Similar but weaker low-latitude anomalies are also seen in JulySeptember, whereas anomalies over the extratropical Atlantic are much weaker in this season.

The emergence of widespread Atlantic cooling and significant atmospheric circulation anomalies at the same time suggests a link between the two. The MSLP 
anomaly pattern seen in October-June is consistent with enhanced westerly winds over the SPG and enhanced northeasterly trade winds over the TNA. These anomalous winds will have acted to cool the ocean surface in these regions through enhanced sensible and latent heat fluxes. The wind anomalies could also have favored an increase in the transport of dust from North Africa over the TNA region, which would also have acted to cool the ocean surface. Finally, alongshore wind anomalies may have enhanced coastal upwelling on the eastern side of the Atlantic and Pacific basins.

\section{d. $1976-1980$}

In the last stage of the event, cool anomalies retreated back to higher latitudes in both October-June and JulySeptember, leaving significant cool anomalies only in the SPG region and in the Mediterranean. The strong MSLP anomalies of the previous stage are no longer seen, implying only weak circulation anomalies.

\section{e. Time series}

The previous results demonstrate that the strongest signals are seen in the extended winter (October-June) season. We now examine the time evolution of the SST and MSLP during October-June for a few key regions in more detail.

Figures 5 and 6 show (October-June) time series of SST and MSLP indices for the regions indicated in Fig. 3. The rapid initial cooling and then recovery of SSTs in the Gulf Stream extension (GSE), as seen in Fig. 3, is apparent in the time series. From the early 1960s the variation of SSTs in the SPG region is almost out of phase with the variation in the GSE region, and these indices are significantly anticorrelated (correlation coefficient is -0.63 over the period 1940-90 when both indices have a long-term trend removed). Similar anticorrelations between these regions are seen in ocean models forced by wind patterns associated the NAO (e.g., Visbeck et al. 1998; Lohmann et al. 2009; Eden and Jung 2001). However, a similar anticorrelation is also seen in some coupled models following a change in the AMOC (Zhang 2008). The cooling of the SPG extends from the mid-1960s through to the mid-1970s and is not entirely within the 1968-72 period highlighted by Thompson et al. (2010). In the tropical North Atlantic region, the magnitude of interannual variability, compared to decadal variability, is relatively high compared to the higher-latitude regions. As noted above, the cooling occurs later, in the early 1970s, than in the SPG.

The MSLP time series (Fig. 6) shows anticorrelated variations in the polar and Atlantic regions in the period of interest. While the conventional NAO index is defined between Gibraltar and Reykjavik (Jones et al.
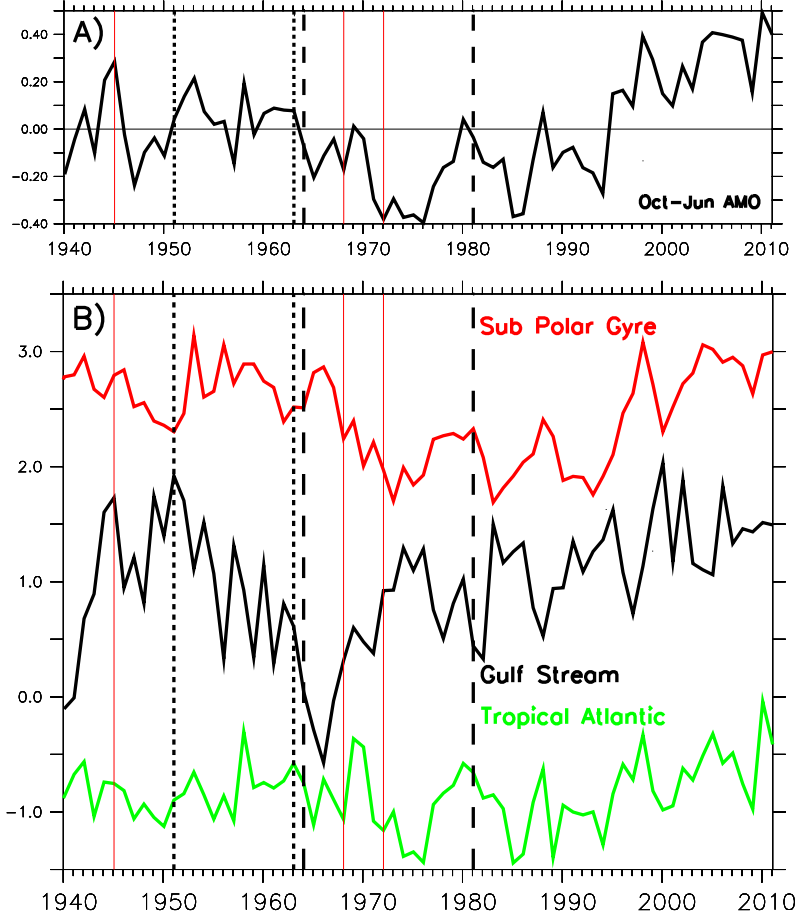

FIG. 5. (a) Observed October-June mean AMO index (see Fig. 1): vertical red lines as in Fig. 1. (b) Sea surface temperature (HadISST) indices for October-June means. The top red line shows the SPG area-weighted mean of $\left(54^{\circ}-63^{\circ} \mathrm{N}, 17^{\circ}-46^{\circ} \mathrm{W}\right)$. The middle black line shows the Gulf Stream region $\left(37^{\circ}-46^{\circ} \mathrm{N}, 67^{\circ}-\right.$ $\left.74^{\circ} \mathrm{W}\right)$. The bottom green line shows the tropical Atlantic $\left(9^{\circ}-22^{\circ} \mathrm{N}\right.$, $\left.14^{\circ}-91^{\circ} \mathrm{W}\right)$. Boxes showing these regions are shown in Fig. 3. Vertical lines are as in Fig. 2. Units are kelvins. Indices in the bottom plot have been offset vertically to aid comparison.

1997), the difference between these two indices (Atlantic - polar) defines an alternative NAO index (Fig. 6, top: blue line). This explains why the well-known post-1960s negative NAO anomalies do not appear in the composite analysis presented in Fig. 3: while the conventional NAO index was more negative during $1964-70(-0.37 \mathrm{hPa})$ than in the reference period (1951$63,-0.05 \mathrm{hPa})$, the difference was much smaller for this alternative NAO index $(1951-63,-0.71 \mathrm{hPa} ; 1964-70$, $-0.91 \mathrm{hPa}$ ). It is notable that, while these two indices are not well correlated during the reference period (195163 , corr $=0.25)$, they are well correlated outside the reference period (1940-50 and 1964-91, corr $=0.70)$. The other notable MSLP anomalies identified in Fig. 3over West African and South American regions-show a decline in MSLP throughout the 1960s and early 1970s, which abruptly ends around 1976 with a rapid return to near pre-1960s values.

\section{f. Sahel rainfall and the ITCZ}

We conducted a similar analysis for temperature and precipitation over land. In both seasons (not shown) 

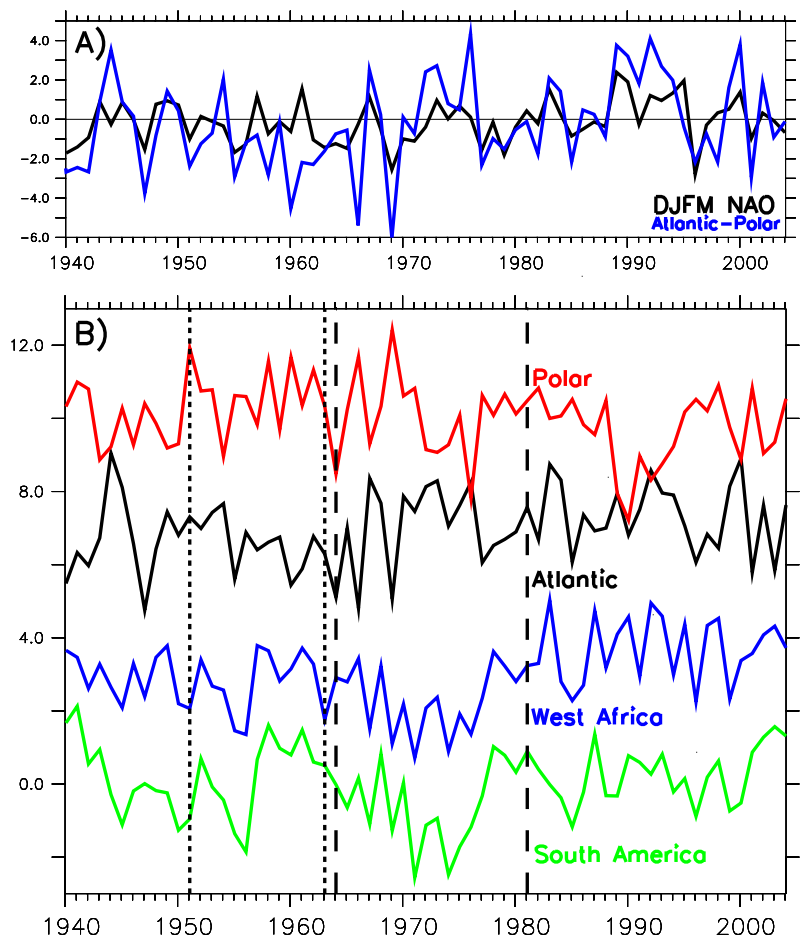

FIG. 6. (a) Observed DJFM NAO anomaly index (black, CRU MSLP: Lisbon-Iceland) and observed October-June dipole anomaly index [blue, Atlantic minus polar indices from (b)] (unit: hPa). Vertical red lines are as in Fig. 1. Both are anomalies with respect to the 1951-2000 mean. (b) Standardized mean sea level pressure indices for October-June means. The top red line shows the polar area-weighted mean of HadSLP over $\left(70^{\circ}-83^{\circ} \mathrm{N}\right.$, $\left.11^{\circ}-135^{\circ} \mathrm{W}\right)$. The upper black line is for the Atlantic $\left(39^{\circ}-50^{\circ} \mathrm{N}\right.$, $\left.12^{\circ}-45^{\circ} \mathrm{W}\right)$. The lower blue line is for West Africa $\left(3^{\circ}-18^{\circ} \mathrm{N}, 9^{\circ} \mathrm{W}-\right.$ $\left.40^{\circ} \mathrm{E}\right)$. The bottom green line is for South America $\left(3^{\circ}-20^{\circ} \mathrm{S}, 4^{\circ}-\right.$ $\left.60^{\circ} \mathrm{W}\right)$. Boxes showing these regions are shown in Fig. 3. Vertical dashed and dotted lines are as in Fig. 2.

there were very few significant anomalies in either field for any of the periods. One notable exception was the well-known rainfall trend over the Sahel region (Nicholson 1980). Many studies have previously commented upon the relationship between the Atlantic multidecadal oscillation (AMO) and the Sahel drying trend, both modeled and observed (e.g., Folland et al. 1986; Zhang and Delworth 2006; Mohino et al. 2011): we examine this link in Fig. 7. It is clear that the drying trend began at the same time as the Atlantic cooling trend (1963/64), but the rainfall did not just follow a simple linear trend: it also exhibits a marked amount of multiannual variability as well. This variability displays some of the characteristics of the multiannual variations in the AMO (Fig. 7, top). Indeed, the Sahel precipitation is significantly correlated with the AMO (Fig. 7, top) [ONDJFMAMJ 1960-2009, $0.42(p<0.01)$ ], once linear trends are removed from both. It is also notable that the substantial dry anomalies that occurred in the 1970s are
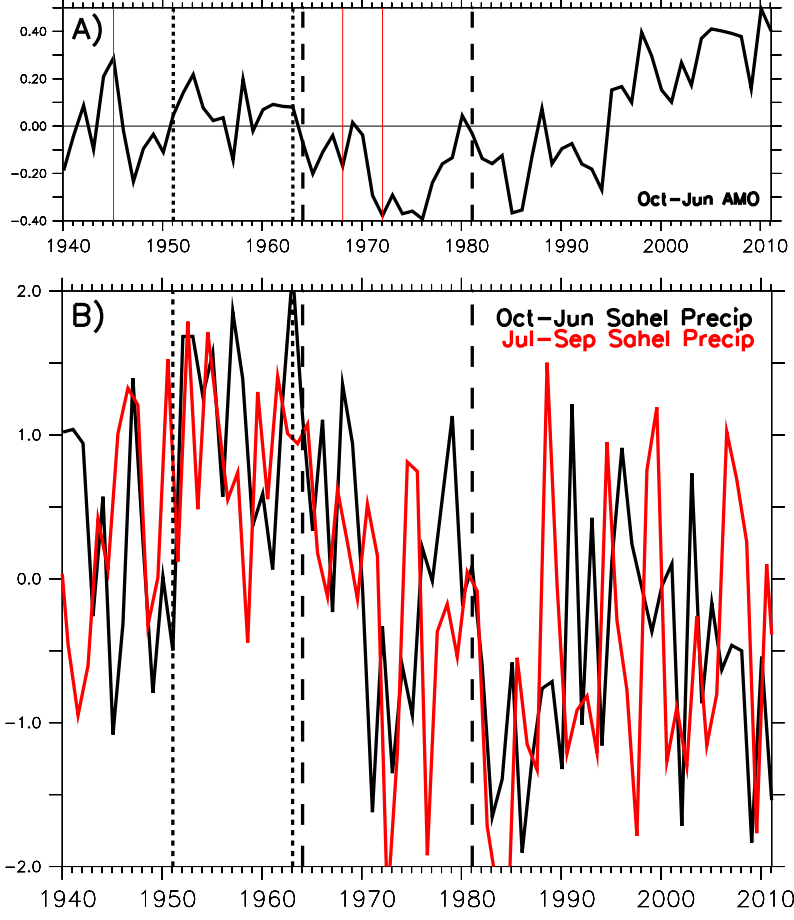

FIG. 7. (a) Observed October-June mean AMO index (see Fig. 1); vertical red lines as in Fig. 1. (b) Rainfall (GPCC precipitation) over the Sahel region $\left(3^{\circ}-18^{\circ} \mathrm{N}, 9^{\circ} \mathrm{W}-40^{\circ} \mathrm{E}\right)$ for October-June (black) and July-September (red). Both indices have been standardized to have unit variance: there is greater rainfall variance in July-September $(\sigma=139 \mathrm{~mm})$ than in OctoberJune $(\sigma=49 \mathrm{~mm})$. Vertical lines are as in Fig. 2.

associated with the low MSLP anomalies seen in Figs. 3 and 4 . The anomalies in precipitation and MSLP may be linked dynamically by a southward shift of the ITCZ (Baines and Folland 2007).

\section{g. Subpolar gyre salinity}

The cooling - and subsequent rewarming-of the SPG (Fig. 5) was accompanied by highly correlated changes in surface salinity (Fig. 8a). The initial cooling and freshening in the later 1960s is the well-documented Great Salinity Anomaly (Dickson et al. 1988; Belkin et al. 1998). These anomalies in temperature and salinity were not confined to the surface: notable anomalies also occurred between the 700-m and 2500-m depth (Fig. 8b). Over this depth range temperature and salinity variations show less high-frequency variability and lag the low-frequency variations at the surface by around $5 \mathrm{yr}$ (correlation at this lag is 0.68 ).

The ocean analyses suggest that SPG density in the 700-2500-m layer declined between the early 1960s and early 1970 s before rising again (Fig. 8c). Model simulations suggest that this decline in density could have caused a decline in the AMOC (Hodson and Sutton 

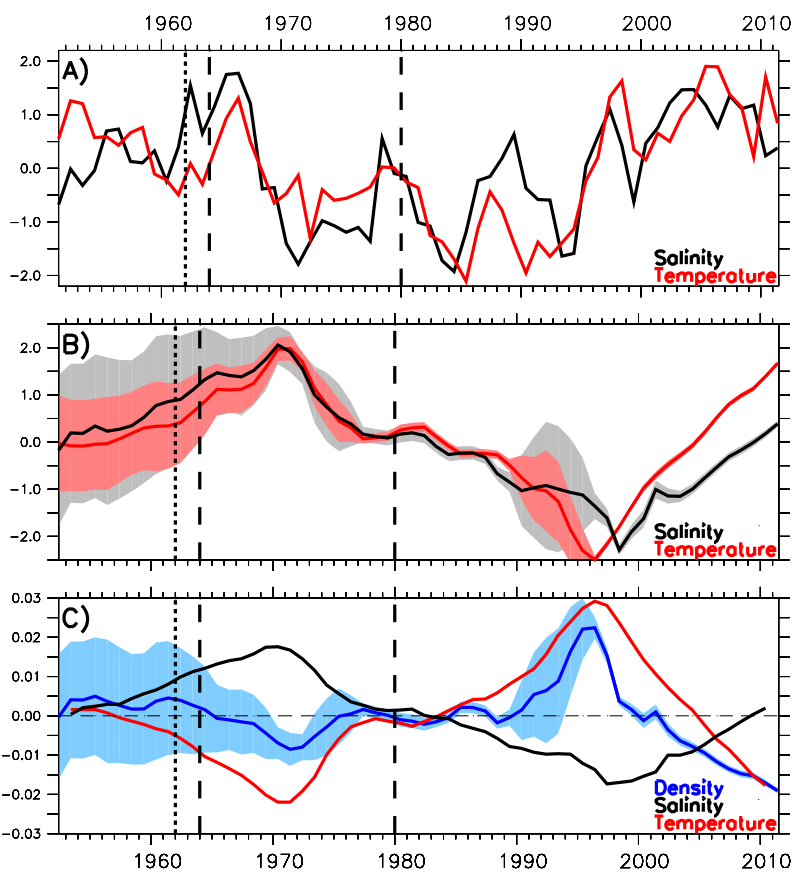

FIG. 8. Temperature and salinity in the subpolar gyre region: (a) area-weighted mean SST (red) and salinity (5-m salinity, black) over the region $\left(50^{\circ}-60^{\circ} \mathrm{N}, 25^{\circ}-55^{\circ} \mathrm{W}\right)$. Both indices are standardized to have unit variance. (b) Area- and depth-weighted mean temperature and salinity (from EN3, see section 2) averaged over the western subpolar gyre region $\left(50^{\circ}-65^{\circ} \mathrm{N}, 35^{\circ}-70^{\circ} \mathrm{W}\right)$ and 700 $2500 \mathrm{~m}$. Both indices have been smoothed with a 5-yr running mean filter and then standardized to have unit variance. (c) Shown in blue is the area- and depth-weighted mean density over the western subpolar gyre $\left(50^{\circ}-65^{\circ} \mathrm{N}, 35^{\circ}-70^{\circ} \mathrm{W}\right)$ and $700-2500 \mathrm{~m}$ and reference pressure of 2000 dbar [e.g., $\rho(T, S, 2000)]$. Shown in black is the contribution to mean density from variations in salinity [e.g., $\rho(\bar{T}, S, 2000)]$. Shown in red is the contribution to mean density from variations in temperature [e.g., $\rho(T, \bar{S}, 2000)]$. All three density indices have been smoothed by a 5 -yr running mean filter (unit: $\mathrm{kg} \mathrm{m}^{-3}$ ). Vertical lines are as in Fig. 2. The shaded regions in (b),(c) show an estimate of the $90 \%$ confidence interval for the observed time series. For details, see the appendix.

2012; Häkkinen 1999), a theory lent specific support by the decadal predictions analyzed by Robson et al. (2014). Ocean assimilations of observed temperature and salinity also suggest that there was a reduction of northward heat transport within the SPG between 1960 and 1976 (Huck et al. 2008), consistent with a reduction of the AMOC over this period.

Rather than being a direct response to the freshening associated with the GSA, Fig. 8b shows that the decline in density was caused by an increase in temperature that began no later than the 1950s and may be linked to the so-called early twentieth-century warming (ETCW) (Brönnimann 2009), although changes in the Nordic Sea deep convection due to the local freshening associated with the GSA may also have played a role via changes in the overflow water. However, the link between the GSA and deep convection in the Nordic Seas at this time is not well understood (Malmberg and Jónsson 1997).

\section{Discussion}

We have demonstrated that the cooling of the North Atlantic Ocean in the 1960s and 1970s proceeded in several distinct stages.

-1964-68: Cool anomalies initially appeared in the seas north of Iceland and in the Gulf Stream extension.

- 1968-72: Cool anomalies spread to cover most of the subpolar gyre, also extending into the higher midlatitudes.

- 1972-76: The North Atlantic basin-mean SST reached its minimum values, with the primary cool anomalies found in tropical North Atlantic and in the subpolar gyre.

- 1976-80: Cool anomalies retreated back to the subpolar gyre.

We have also assembled evidence concerning some of the processes that may have contributed to the observed sequence of events. In this section, we discuss 1) the possible roles of specific processes in the ocean and/or atmosphere and 2) the possible roles of changes in external forcing factors (Fig. 2). Figure 9 provides a schematic summarizing the various mechanisms involved.

\section{a. Ocean/atmosphere processes involved in the North Atlantic cooling}

As noted in the previous section, the cooling of the subpolar gyre in the late 1960s and early 1970s occurred at the same time as a freshening (Fig. 8a): the wellknown Great Salinity Anomaly (Dickson et al. 1988; Belkin et al. 1998). This anomaly is thought to have arisen due to the advection of cold, fresh waters from north of Iceland, possibly originating from an anomalous Arctic freshwater/sea ice pulse via Fram Strait (Häkkinen 1993; Belkin et al. 1998). This pulse may, in turn, have been generated by anomalous northerly winds during the late 1950s and early 1960s (Dickson et al. 1988).

A simple scenario for the initial cooling of the subpolar North Atlantic is, therefore, that it reflects a spreading of anomalously cool, fresh GSA waters of Arctic origin. This direct cooling influence may have been amplified by changes in ocean circulation, in particular a reduction in northward heat transport related to a possible slowdown in the Atlantic meridional overturning circulation. Such a slowdown is supported by evidence of subsurface density trends in the SPG and by the decadal hindcasts analyzed by Robson et al. (2014). As already noted, SPG density was falling 


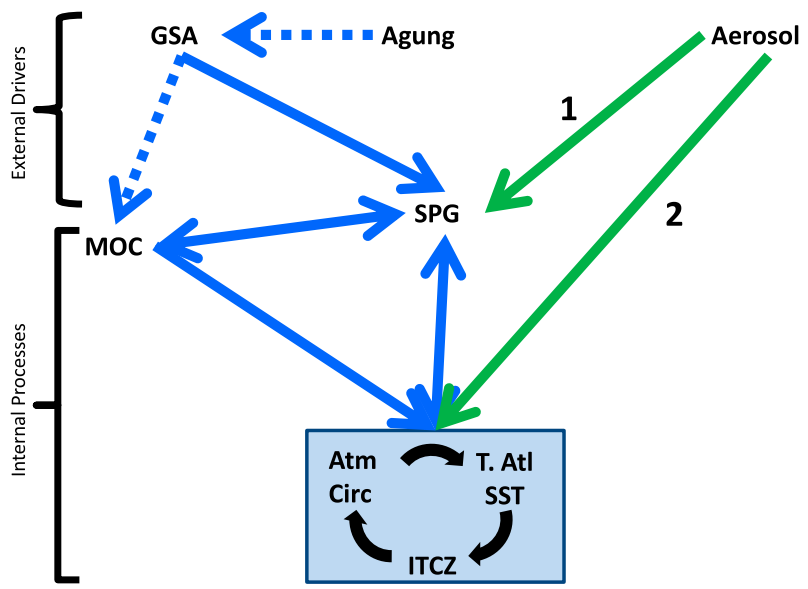

FIG. 9. Schematic describing the proposed mechanisms for explaining the observed North Atlantic cooling.

throughout the 1950s and 1960s, associated with a decadal time-scale warming. It is possible that the cooling of the Gulf Stream extension region over this period (Fig. 5) was linked to a slowdown in the AMOC, although wind forcing of the gyre circulation might also have played a role.

A striking feature of the observed evolution (Fig. 3) is the appearance in 1972-76 of significant anomalies in atmospheric circulation, similar in winter to the positive phase of the NAO, at the time when cool SST anomalies first appeared in the tropical North Atlantic, and North Atlantic basin-mean SST reached its minimum values. This was also the time when serious drought in the Sahara first occurred (Fig. 7). As noted previously, the anomalous SLP gradients suggest that enhanced turbulent heat fluxes associated with increased surface wind speeds are likely to have contributed to the cooling of SST in both the SPG and TNA regions. Enhanced advection of dust from the Sahara over the TNA region may also have contributed to the cooling of SST at this time (Foltz and McPhaden 2008; Wang et al. 2012).

An important question is why did the anomalies in atmospheric circulation occur? The significance of these anomalies suggests that it is unlikely they merely reflect a random fluctuation in the atmosphere. One possibility, discussed in the next section, is that they were a response to changing external forcings. Another (not necessarily independent) possibility is that they arose in response to the cooling of SST in the SPG. There is evidence that the atmospheric response to cool SSTs in the SPG projects on the positive phase of the NAO (consistent with Fig. 3), although there is considerable uncertainty about the magnitude of this response (Hodson and Sutton 2012; Gastineau and Frankignoul 2012; Omrani et al. 2014). In addition, there is increasing evidence that extratropical SST anomalies can influence lower latitudes via atmospheric teleconnections. Kang et al. (2009) demonstrated that extratropical SST anomalies can displace the intertropical convergence zone (ITCZ) by changing the meridional heat transport in the atmosphere. Cloud feedback mechanisms are particularly important in setting the magnitude of this response. Similar tropical responses are also seen in coupled climate models when the AMOC is suppressed by a northern freshwater pulse (Zhang et al. 2010).

The wind-evaporation-SST (WES) feedback mechanism may have played a role in propagating a signal from the extratropics into the tropical Atlantic and/or in amplifying the response in the tropics where there is close coupling between SST, the ITCZ, and atmospheric circulation (Fig. 9) (Vimont 2012; Xie 1999; Mahajan et al. 2011). Smirnov and Vimont (2012) demonstrated this mechanism in a coupled atmosphere mixed-layer model, showing that extratropical SST anomalies can drive tropical SST anomalies of the same sign some months later.

Figure 3 shows that tropical Atlantic SST anomalies only persisted as long as the MSLP anomalies (1972-76), whereas the subpolar SST anomalies persisted over a longer period (1968-80), supporting the hypothesis that the tropical anomalies may have been forced from the extratropics, and not vice versa. This hypothesis is also supported by the lagged correlation between SSTs and SPG SSTs (Fig. 10): SSTs in the tropical Atlantic clearly lag those in the SPG, with a spatial pattern similar to the SST anomaly pattern at the depth of the cooling (Fig. 3). This cross-correlation between tropical North Atlantic and SPG SSTs shows a maximum of $0.46(p<0.05)$ when the tropical Atlantic lags the SPG by 2 yr. Finally, this hypothesis might also offer an explanation for why many climate models exhibit AMVrelated SST anomalies in the tropical Atlantic that are too weak by comparison with observations (Martin et al. 2014): these weak signals could be a consequence of the too-weak atmospheric response to AMV-related SST variations in the extratropical North Atlantic.

In summary, there is evidence that the GSA, changes in ocean circulation, and changes in atmospheric circulation all played roles in the 1960s cooling of the North Atlantic. One scenario is that the GSA and the decadal time-scale warming of the SPG (following the ETCW) were both important triggers. The former led to a direct cooling of the SPG SST, while the latter caused additional cooling via a slowdown in the AMOC. Subsequently, the cooling of the SPG triggered changes in atmospheric circulation [consistent with the hypothesis of Zhang and Delworth (2006)] that helped to propagate the cooling into the tropical North Atlantic. These interactions are illustrated in Fig. 9. 

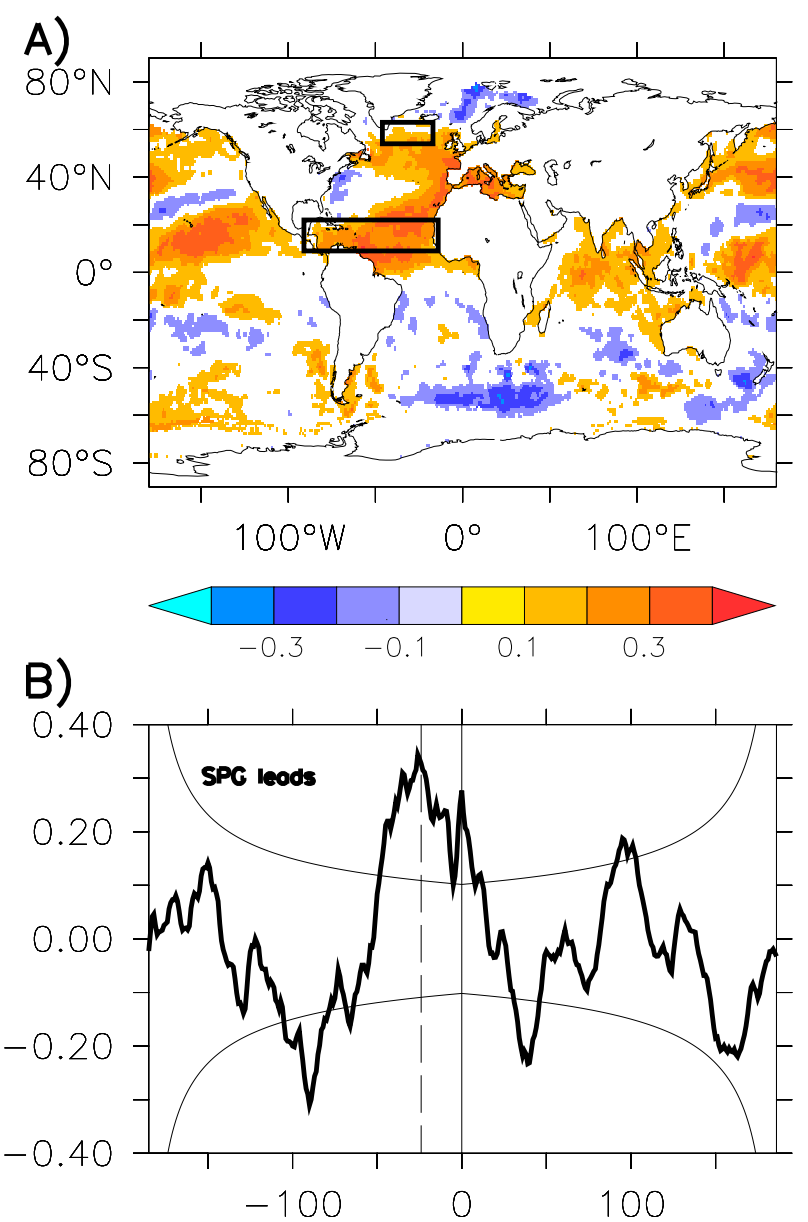

FIG. 10. (a) For 1960-91, the SST at each grid point is lag correlated with the subpolar gyre SST index (upper box: $50^{\circ}-60^{\circ} \mathrm{N}$, $25^{\circ}-55^{\circ} \mathrm{W}$ ). Monthly mean SSTs are used with the mean seasonal cycle removed with the SPG index leading SST by 2 yr at each grid point. (B) Lag correlations for the SPG index with tropical North Atlantic SST [lower box in (a)]. Thin black curves show simple measure of correlation significance $(p<0.05)$.

\section{b. The role of external forcing factors}

As noted previously, many of the external climate forcings changed markedly during the 1960s and 1970s (Fig. 2). Sulfur dioxide emissions rose throughout the period, as did $\mathrm{CO}_{2}$ emissions. It was also a period of increased volcanic activity, ending the hiatus of the previous $30 \mathrm{yr}$. Solar irradiance also fell, with a $17-\mathrm{yr}$ mean of $1366.01 \mathrm{~W} \mathrm{~m}^{-2}$ compared to $1366.06 \mathrm{~W} \mathrm{~m}^{-2}$ for the $17 \mathrm{yr}$ both before and after this period (1947-63 and 1981-97). This minimum is perhaps even more pronounced in the open solar flux, an alternative measure of solar activity (Lockwood et al. 2009).

The eruption of Agung in 1963/64, which was followed by smaller eruptions in 1968/69 and 1975 (Sato et al. 1993), could have contributed to the North Atlantic cooling. While the initial pattern of the observed cooling (Figs. 3 and 4, panels for 1964-68) shows no obvious correspondence with the expected response to a volcanic eruption, Swingedouw et al. (2013) argue that, in their climate model, the Agung eruption resets the phase of an internal mode of decadal variability (see also Ottera et al. 2010). Such a resetting could potentially occur as a direct response to the surface cooling induced by an eruption or in response to anomalies in the atmospheric circulation triggered by the eruption. Whether such mechanisms may have operated in the real world following the Agung eruption is very hard to ascertain. It is conceivable that wind anomalies caused by Agung might have played a role in forcing the GSA, but we are not aware of any direct evidence for this. Note that the observed positive NAO anomaly in 197276 (Fig. 3) occurred too long after Agung to be explained by a direct response to this eruption.

The direct influence of the decline in solar radiation is also hard to reconcile with the observed space-time evolution of the cooling signal. The decline in forcing might have been expected to force a negative NAO response (Ineson et al. 2011), but this is opposite to the positive NAO anomaly observed in 1972-76.

Booth et al. (2012) suggested that a reduction in surface shortwave radiation owing to aerosol forcing (resulting from the increase in sulfur dioxide emissions from North America and Europe) was the dominant driver of the cooling event. However, the ensemble mean response of their model simulations did not reproduce the observed space-time evolution of the SST changes and other variables (Zhang et al. 2013). It is very likely that sulfate concentrations over the North Atlantic were high during the period of the cooling, being advected by the mean winds from the continental United States and European sources (Booth et al. 2012). Previous studies have demonstrated that sulfate aerosols can cool the oceans (Williams et al. 2001; Rotstayn and Lohmann 2002; Ming and Ramaswamy 2009; Chang et al. 2011. However, the cloud properties over the SPG may not be optimal for sulfate aerosols to have this impact: Booth et al. (2012) showed low shortwave (SW) anomalies owing to the aerosol first indirect effect over the North Atlantic, but the largest modeled shortwave radiation anomalies were in the middle and low latitudes. It is plausible, therefore, that sulfate aerosol forcing contributed to the cooling of SST in these regions but less likely that aerosol forcing had a substantial direct impact on the cooling of the SPG. This influence might have been independent of the influence of the anomalous atmospheric circulation seen in 1972-76; alternatively, it is possible that aerosol forcing played a role in forcing 
the atmospheric circulation, although there is no evidence of this in the results of Booth et al. (2012). We note again that Saharan dust is an important component of aerosol over the tropical North Atlantic, and the relative importance of changes in dust and changes in sulfate aerosol for the cooling of the North Atlantic in the 1960s and 1970s is an open question.

In summary, if natural radiative forcing played a role in the North Atlantic cooling, the most likely mechanism is that the eruption of Agung played a role in generating surface wind anomalies over the Arctic that in turn triggered the GSA. Concerning anthropogenic forcing, it is likely that sulfate aerosols contributed to the cooling, but the observed space-time evolution cannot be explained as a direct response to sulfate forcing, and it is highly likely that other factors were important, as summarized in Fig. 9.

\section{Conclusions}

During the 1960s and 1970s sea surface temperatures in the North Atlantic Ocean cooled rapidly. Linked to this cooling were significant changes in climate in many regions. The key findings from this study are as follows and key mechanisms are summarized in Fig. 9.

- The cooling of the North Atlantic proceeded in several distinct stages. Cool anomalies initially appeared in the mid-1960s in the Nordic Seas and Gulf Stream extension, before spreading to cover most of the subpolar gyre. Subsequently, cool anomalies spread into the tropical North Atlantic before retreating, in the late 1970s, back to the subpolar gyre. Theories for the cooling event must account for this distinctive spacetime evolution.

- There is strong evidence linking the initial cooling of the subpolar North Atlantic (in the late 1960s) to an outflow of anomalously cool freshwater from the Arctic: the Great Salinity Anomaly (GSA).

- There is strong evidence that changes in atmospheric circulation played an important role in the cooling event, particularly in the period 1972-76, when the cooling spread into the tropical North Atlantic. This spreading is associated with a pattern of winter SLP anomalies that projects on the positive phase of the North Atlantic Oscillation and favors cooling of SST through enhanced turbulent heat fluxes and possibly enhanced advection of Saharan dust over the tropical North Atlantic. The anomalous atmospheric circulation might have developed in response to the cooling of the subpolar North Atlantic (Zhang and Delworth 2006; Smirnov and Vimont 2012) or in response to changes in radiative forcing (see below). The changes in atmospheric circulation are linked to a southward shift of the Atlantic ITCZ at the same time.

- There is evidence that changes in ocean circulation, in particular a slowdown in the Atlantic meridional overturning circulation (AMOC), may have contributed to the North Atlantic cooling. Such a slowdown is most likely to have been a consequence of an earlier decadal time-scale warming of the subpolar North Atlantic (linked to the early twentieth-century warming), rather than being directly driven by the GSA. We also recognize that changes in deep convection in the Nordic Seas related to the GSA could also have played a role in the decline of the AMOC beginning in the late 1960s. However, the link between the GSA and deep convection in the Nordic Seas at this time is not well understood (Malmberg and Jónsson 1997).

- There were significant changes in natural radiative forcing during the cooling event, in particular a decline in solar forcing and the eruption of Agung in 1963/64 [which was followed by smaller eruptions in 1968/69 and 1975, Sato et al. (1993)]. However, there is little evidence of a direct link between these changes in radiative forcing and the observed evolution of the cooling event. It is possible that the eruption of Agung might have played a role in triggering the GSA via an influence on the winds over the Arctic, but there is no firm evidence of such a link.

- There was a significant increase in sulfur dioxide emissions from North America and Europe during the cooling event. Booth et al. (2012) suggested that the resulting anthropogenic aerosol forcing was the dominant driver of the cooling event; however, the ensemble mean response of their model simulations did not reproduce the observed space-time evolution of the event (Zhang et al. 2013). Our results suggest it is likely that aerosol forcing contributed to the cooling but other factors such as the GSA and the AMOC were also important. It is possible that aerosol forcing contributed to the observed changes in atmospheric circulation, which contributed to the cooling event, but this hypothesis will need testing in future work.

In summary, our analysis suggests that the most likely drivers of the cooling event were 1) the GSA (the trigger for which is uncertain); 2) an earlier warming of the subpolar North Atlantic, which may have led to a slowdown in the AMOC; and 3) the increase in anthropogenic sulfur dioxide emissions. Because we have focused on observations, we recognize of course that the evidence presented in this study is mostly circumstantial. Further testing of these hypotheses using models, including determining quantitatively the relative importance of the different drivers, is a key area for future work. 
Acknowledgments. The authors wish to thank the National Centre for Atmospheric Science (NCAS) and the Natural Environmental Research Council (NERC) for support during this work. Jon Robson was also supported by the Projet Prévisibilit Climatique Decennale (PRECLIDE) and the Seasonal-to-decadal climate Prediction for the improvement of European Climate Service project (SPECS) GA 308378. The authors wish to thank all the producers of the datasets upon which this paper rests: Tracey Basnett, David Parker, Nick Rayner, and others at the Met Office for GMSLP, HadISST, and EN3; NOAA/OAR/ESRL (PSD, Boulder, Colorado) for their GPCC precipitation dataset (www.esrl.noaa.gov/psd/); Yi-Ming Wang, Judith Lean, and Neil Sheeley the reconstructions of TSI; Mike Lockwood for the open solar flux estimates; and Makiko Sato for the stratospheric aerosols database. The authors also wish to acknowledge use of the Ferret program for analysis and graphics in this paper. Ferret is a product of NOAA's Pacific Marine Environmental Laboratory (information is available at http://ferret.pmel.noaa.gov/Ferret/).

\section{APPENDIX}

\section{Observational Error Estimates for Figure 8}

The estimates of observed error shown by shading in Figs. 8b,c were obtained using a similar method to Palmer and Brohan (2011), as follows. Monthly mean data (after a 2-yr running mean was removed) was binned into bins of 30 according to the total number of observations at the $1250-\mathrm{m}$ and $2250-\mathrm{m}$ depths. The standard error is then parameterized by regressing the within-bin variance onto the bin-mean number of observations across all bins. Note that, since the EN3 data will tend to climatology in the absence of observations (Ingleby and Huddleston 2007), bins with a low average number of observations [for this case, $1 / \operatorname{SQRT}(N)<$ $0.1]$ were ignored. Also note that the regression is forced to cross the origin as in Palmer and Brohan (2011). To account for months with very low numbers of observations, the 5-yr running-mean confidence limits were calculated from 10000 Monte Carlo simulations of the monthly time series. Specifically, perturbed time series were produced by adding the standard error for each month (which is dependent on the total number of observations) by a random number generated from a normal distribution with mean equal to 0 and standard deviation equal to 1 . The Monte Carlo simulations were then used to find the 5th and 95th percentiles to give the $90 \%$ confidence interval. Finally, for density, the errors are calculated in the same way (i.e., after the density index is computed), but the error is fitted using the number of salinity observations.

\section{REFERENCES}

Allan, R., and T. Ansell, 2006: A new globally complete monthly historical gridded mean sea level pressure dataset (HadSLP2): 1850-2004. J. Climate, 19, 5816-5842, doi:10.1175/JCLI3937.1.

Baines, P. G., and C. K. Folland, 2007: Evidence for a rapid global climate shift across the late 1960s. J. Climate, 20, 2721-2744, doi:10.1175/JCLI4177.1.

Becker, A., P. Finger, A. Meyer-Christoffer, B. Rudolf, K. Schamm, U. Schneider, and M. Ziese, 2013: A description of the global land-surface precipitation data products of the Global Precipitation Climatology Centre with sample applications including centennial (trend) analysis from 1901present. Earth Syst. Sci. Data, 5, 71-99, doi:10.5194/essd-5-71-2013.

Belkin, I. M., S. Levitus, J. Antonov, and S.-A. Malmberg, 1998: Great salinity anomalies in the North Atlantic. Prog. Oceanogr., 41, 1-68, doi:10.1016/S0079-6611(98)00015-9.

Booth, B. B. B., N. J. Dunstone, P. R. Halloran, T. Andrews, and N. Bellouin, 2012: Aerosols implicated as a prime driver of twentieth-century North Atlantic climate variability. Nature, 484, 228-232, doi:10.1038/nature10946.

Brönnimann, S., 2009: Early twentieth-century warming. Nat. Geosci., 2, 735-736, doi:10.1038/ngeo670.

Chang, C.-Y., J. C. H. Chiang, M. F. Wehner, A. R. Friedman, and R. Ruedy, 2011: Sulfate aerosol control of tropical Atlantic climate over the twentieth century. J. Climate, 24, 2540-2555, doi:10.1175/2010JCLI4065.1.

Condron, A., P. Winsor, C. Hill, and D. Menemenlis, 2009: Simulated response of the Arctic freshwater budget to extreme NAO wind forcing. J. Climate, 22, 2422-2437, doi:10.1175/ 2008JCLI2626.1.

Dickson, R. R., J. Meincke, S.-A. Malmberg, and A. J. Lee, 1988: The Great Salinity Anomaly in the northern North Atlantic 1968-1982. Prog. Oceanogr., 20, 103-151, doi:10.1016/ 0079-6611(88)90049-3.

Dong, B., and R. T. Sutton, 2007: Enhancement of ENSO variability by a weakened Atlantic thermohaline circulation in a coupled GCM. J. Climate, 20, 4920-4939, doi:10.1175/ JCLI4284.1.

Eden, C., and T. Jung, 2001: North Atlantic interdecadal variability: Oceanic response to the North Atlantic Oscillation (1865-1997). J. Climate, 14, 676-691, doi:10.1175/ 1520-0442(2001)014<0676:NAIVOR >2.0.CO;2.

Enfield, D. B., A. M. Mestas-Nuñez, and P. J. Trimble, 2001: The Atlantic multidecadal oscillation and its relation to rainfall and river flows in the continental U.S. Geophys. Res. Lett., 28 , 2077-2080, doi:10.1029/2000GL012745.

Folland, C. K., T. N. Palmer, and D. E. Parker, 1986: Sahel rainfall and worldwide sea temperatures, 1901-85. Nature, 320, 602607, doi:10.1038/320602a0.

— , A. W. Colman, D. P. Rowell, and M. K. Davey, 2001: Predictability of northeast Brazil rainfall and real-time forecast skill, 1987-98. J. Climate, 14, 1937-1958, doi:10.1175/ 1520-0442(2001)014<1937:PONBRA > 2.0.CO;2.

Foltz, G. R., and M. J. McPhaden, 2008: Trends in Saharan dust and tropical Atlantic climate during 1980-2006. Geophys. Res. Lett., 35, L20706, doi:10.1029/2008GL035042.

Friedman, A. R., Y.-T. Hwang, J. C. H. Chiang, and D. M. W. Frierson, 2013: Interhemispheric temperature asymmetry over the twentieth century and in future projections. J. Climate, 26, 5419-5433, doi:10.1175/JCLI-D-12-00525.1.

Gastineau, G., and C. Frankignoul, 2012: Cold-season atmospheric response to the natural variability of the Atlantic meridional 
overturning circulation. Climate Dyn., 39 (1-2), 37-57, doi:10.1007/s00382-011-1109-y.

Goldenberg, S. B., C. W. Landsea, A. M. Mestas-Nuñez, and W. M. Gray, 2001: The recent increase in Atlantic hurricane activity: Causes and implications. Science, 293, 474-479, doi:10.1126/ science. 1060040.

Graft, H. F., I. Kirchner, A. Robock, and I. Schult, 1993: Pinatubo eruption winter climate effects: Model versus observations. Climate Dyn., 9, 81-93, doi:10.1007/BF00210011.

Gray, L. J., S. T. Rumbold, and K. P. Shine, 2009: Stratospheric temperature and radiative forcing response to 11-year solar cycle changes in irradiance and ozone. J. Atmos. Sci., 66, 24022417, doi:10.1175/2009JAS2866.1.

— - and Coauthors, 2010: Solar influences on climate. Rev. Geophys., 48, RG4001, doi:10.1029/2009RG000282.

Haigh, J. D., 1999: A GCM study of climate change in response to the 11-year solar cycle. Quart. J. Roy. Meteor. Soc., 125, 871892, doi:10.1002/qj.49712555506.

Häkkinen, S., 1993: An Arctic source for the Great Salinity Anomaly: A simulation of the arctic ice-ocean system for 1955-1975. J. Geophys. Res., 98, 16397-16410, doi:10.1029/ 93JC01504.

1999: A simulation of thermohaline effects of a Great Salinity Anomaly. J. Climate, 12, 1781-1795, doi:10.1175/ 1520-0442(1999)012<1781:ASOTEO > 2.0.CO;2.

Haywood, J., and O. Boucher, 2000: Estimates of the direct and indirect radiative forcing due to tropospheric aerosols: A review. Rev. Geophys., 38, 513-543, doi:10.1029/1999RG000078.

Hodson, D. L. R., and R. T. Sutton, 2012: The impact of resolution on the adjustment and decadal variability of the Atlantic meridional overturning circulation in a coupled climate model. Climate Dyn., 39, 3057-3073, doi:10.1007/s00382-012-1309-0.

Hoerling, M., J. Hurrell, J. Eischeid, and A. Phillips, 2006: Detection and attribution of twentieth-century northern and southern African rainfall change. J. Climate, 19, 3989-4008, doi:10.1175/JCLI3842.1.

Huck, T., A. C. de Verdière, P. Estrade, and R. Schopp, 2008: Lowfrequency variations of the large-scale ocean circulation and heat transport in the North Atlantic from 1955-1998 in situ temperature and salinity data. Geophys. Res. Lett., 35, L23613, doi:10.1029/2008GL035635.

Ineson, S., A. A. Scaife, J. R. Knight, J. C. Manners, N. J. Dunstone, L. J. Gray, and J. D. Haigh, 2011: Solar forcing of winter climate variability in the Northern Hemisphere. Nat. Geosci., 4, 753-757, doi:10.1038/ngeo1282.

Ingleby, B., and M. Huddleston, 2007: Quality control of ocean temperature and salinity profiles historical and real-time data. J. Mar. Syst., 65 (1-4), 158-175, doi:10.1016/ j.jmarsys.2005.11.019.

Iwi, A. M., L. Hermanson, K. Haines, and R. T. Sutton, 2012: Mechanisms linking volcanic aerosols to the Atlantic meridional overturning circulation. J. Climate, 25, 3039-3051, doi:10.1175/2011JCLI4067.1.

Jones, P. D., T. Jonsson, and D. Wheeler, 1997: Extension to the North Atlantic Oscillation using early instrumental pressure observations from Gibraltar and south-west Iceland. Int. J. Climatol., 17, 1433-1450, doi:10.1002/(SICI)1097-0088(19971115)17: $13<1433::$ AID-JOC203>3.0.CO;2-P.

Kang, S. M., D. M. W. Frierson, and I. M. Held, 2009: The tropical response to extratropical thermal forcing in an idealized GCM: The importance of radiative feedbacks and convective parameterization. J. Atmos. Sci., 66, 2812-2827, doi:10.1175/ 2009JAS2924.1.
Knight, J. R., C. K. Folland, and A. A. Scaife, 2006: Climate impacts of the Atlantic multidecadal oscillation. Geophys. Res. Lett., 33, L17706, doi:10.1029/2006GL026242.

Lean, J., 2000: Evolution of the sun's spectral irradiance since the maunder minimum. Geophys. Res. Lett., 27, 2425-2428, doi:10.1029/2000GL000043.

Lockwood, M., A. P. Rouillard, and I. D. Finch, 2009: The rise and fall of open solar flux during the current grand solar maximum. Astrophys. J., 700, 937, doi:10.1088/0004-637x/700/2/937.

Lohmann, K., H. Drange, and M. Bentsen, 2009: A possible mechanism for the strong weakening of the North Atlantic subpolar gyre in the mid-1990s. Geophys. Res. Lett., 36, L15602, doi:10.1029/2009GL039166.

Mahajan, S., R. Saravanan, and P. Chang, 2011: The role of the wind-evaporation-sea surface temperature (WES) feedback as a thermodynamic pathway for the equatorward propagation of high-latitude sea ice-induced cold anomalies. J. Climate, 24, 1350-1361, doi:10.1175/2010JCLI3455.1.

Malmberg, S.-A., and S. Jónsson, 1997: Timing of deep convection in the Greenland and Iceland Seas. ICES J. Mar. Sci., 54, 300309, doi:10.1006/jmsc.1997.0221.

Mann, M. E., and K. A. Emanuel, 2006: Atlantic hurricane trends linked to climate change. Eos, Trans. Amer. Geophys. Union, 87, 233-241, doi:10.1029/2006EO240001.

Martin, E. R., C. Thorncroft, and B. B. B. Booth, 2014: The multidecadal Atlantic SST-Sahel rainfall teleconnection in CMIP5 simulations. J. Climate, 27, 784-806, doi:10.1175/ JCLI-D-13-00242.1.

McManus, J. F., R. Francois, J. M. Gherardi, L. D. Keigwin, and S. Brown-Leger, 2004: Collapse and rapid resumption of Atlantic meridional circulation linked to deglacial climate changes. Nature, 428, 834-837, doi:10.1038/nature02494.

Meehl, G. A., J. M. Arblaster, K. Matthes, F. Sassi, and H. van Loon, 2009: Amplifying the Pacific climate system response to a small 11-year solar cycle forcing. Science, 325, 1114-1118, doi:10.1126/science.1172872.

Meinshausen, M., and Coauthors, 2011: The RCP greenhouse gas concentrations and their extensions from 1765 to 2300. Climatic Change, 109 (1-2), 213-241, doi:10.1007/ s10584-011-0156-Z.

Ming, Y., and V. Ramaswamy, 2009: Nonlinear climate and hydrological responses to aerosol effects. J. Climate, 22, 1329 1339, doi:10.1175/2008JCLI2362.1.

Mohino, E., S. Janicot, and J. Bader, 2011: Sahel rainfall and decadal to multi-decadal sea surface temperature variability. Climate Dyn., 37 (3-4), 419-440, doi:10.1007/s00382-010-0867-2.

Nicholson, S. E., 1980: The nature of rainfall fluctuations in subtropical West Africa. Mon. Wea. Rev., 108, 473-487, doi:10.1175/1520-0493(1980)108<0473:TNORFI >2.0.CO;2.

Omrani, N. E., N. S. Keenlyside, J. Bader, and E. Manzini, 2014: Stratosphere key for wintertime atmospheric response to warm Atlantic decadal conditions. Climate Dyn., 42 (3-4), 649-663, doi:10.1007/s00382-013-1860-3.

Ottera, O. H., M. Bentsen, H. Drange, and L. Suo, 2010: External forcing as a metronome for Atlantic multidecadal variability. Nat. Geosci., 3, 688-694, doi:10.1038/ngeo955.

Palmer, M. D., and P. Brohan, 2011: Estimating sampling uncertainty in fixed-depth and fixed-isotherm estimates of ocean warming. Int. J. Climatol., 31, 980-986, doi:10.1002/ joc. 2224 .

Rayner, N. A., D. E. Parker, E. B. Horton, C. K. Folland, L. V. Alexander, D. P. Rowell, E. C. Kent, and A. Kaplan, 2003: Global analyses of sea surface temperature, sea ice, and night 
marine air temperature since the late nineteenth century. J. Geophys. Res., 108, 4407, doi:10.1029/2002JD002670.

Robock, A., and J. Mao, 1995: The volcanic signal in surface temperature observations. J. Climate, 8, 1086-1103, doi:10.1175/1520-0442(1995)008<1086:TVSIST>2.0.CO;2.

Robson, J., R. Sutton, and D. Smith, 2014: Decadal predictions of the cooling and freshening of the North Atlantic in the 1960s and the role of ocean circulation. Climate Dyn., 42 (9-10), 2353-2365, doi:10.1007/s00382-014-2115-7.

Rotstayn, L. D., and U. Lohmann, 2002: Tropical rainfall trends and the indirect aerosol effect. J. Climate, 15, 2103-2116, doi:10.1175/1520-0442(2002)015<2103:TRTATI>2.0.CO;2.

Sato, M., J. E. Hansen, M. P. McCormick, and J. B. Pollack, 1993: Stratospheric aerosol optical depths, 1850-1990. J. Geophys. Res., 98, 22 987-22 994, doi:10.1029/93JD02553.

Schneider, U., A. Becker, P. Finger, A. Meyer-Christoffer, M. Ziese, and B. Rudolf, 2014: GPCC's new land surface precipitation climatology based on quality-controlled in situ data and its role in quantifying the global water cycle. Theor. Appl. Climatol., 115 (1-2), 15-40, doi:10.1007/s00704-013-0860-x.

Shapiro, L. J., and S. B. Goldenberg, 1998: Atlantic sea surface temperatures and tropical cyclone formation. J. Climate, 11, 578-590, doi:10.1175/1520-0442(1998)011<0578: ASSTAT $>2.0 . \mathrm{CO} ; 2$.

Smirnov, D., and D. J. Vimont, 2012: Extratropical forcing of tropical Atlantic variability during boreal summer and fall. J. Climate, 25, 2056-2076, doi:10.1175/JCLI-D-11-00104.1.

Smith, S. J., R. Andres, E. Conception, and J. Lurz, 2004: Historical sulfur dioxide emissions 1850-2000: Methods and results. Pacific Northwest National Laboratory Tech Rep. PNNL14537, 16 pp., doi:10.2172/15020102.

— J. van Aardenne, Z. Klimont, R. J. Andres, A. Volke, and S. D. Arias, 2011: Anthropogenic sulfur dioxide emissions: 1850-2005. Atmos. Chem. Phys., 11, 1101-1116, doi:10.5194/ acp-11-1101-2011.

Sutton, R. T., and D. L. R. Hodson, 2005: Atlantic Ocean forcing of North American and European summer climate. Science, 309, 115-118, doi:10.1126/science.1109496.

_ , and _ 2007: Climate response to basin-scale warming and cooling of the North Atlantic Ocean. J. Climate, 20, 891-907, doi:10.1175/JCLI4038.1.

Swingedouw, D., J. Mignot, S. Labetoulle, E. Guilyardi, and G. Madec, 2013: Initialisation and predictability of the AMOC over the last 50 years in a climate model. Climate Dyn., 40 (9-10), 2381-2399, doi:10.1007/s00382-012-1516-8.

Thompson, D. W. J., J. J. Kennedy, J. M. Wallace, and P. D. Jones, 2008: A large discontinuity in the mid-twentieth century in observed global-mean surface temperature. Nature, 453, 646649, doi:10.1038/nature06982.

— J. M. Wallace, J. J. Kennedy, and P. D. Jones, 2010: An abrupt drop in Northern Hemisphere sea surface temperature around 1970. Nature, 467, 444-447, doi:10.1038/nature09394.
Uvo, C. B., C. A. Repelli, S. E. Zebiak, and Y. Kushnir, 1998: The relationships between tropical Pacific and Atlantic SST and northeast Brazil monthly precipitation. J. Climate, 11, 551-562, doi:10.1175/1520-0442(1998)011<0551:TRBTPA>2.0.CO;2.

Vellinga, M., and R. A. Wood, 2002: Global climatic impacts of a collapse of the Atlantic thermohaline circulation. Climatic Change, 54, 251-267, doi:10.1023/A:1016168827653.

Vieira, L. E. A., and S. K. Solanki, 2010: Evolution of the solar magnetic flux on time scales of years to millennia. Astron. Astrophys., 509, A100, doi:10.1051/0004-6361/200913276.

Vimont, D. J., 2012: Analysis of the Atlantic meridional mode using linear inverse modeling: Seasonality and regional influences. J. Climate, 25, 1194-1212, doi:10.1175/JCLI-D-11-00012.1.

Visbeck, M., H. Cullen, G. Krahmann, and N. Naik, 1998: An ocean model's response to North Atlantic Oscillation-like wind forcing. Geophys. Res. Lett., 25, 4521-4524, doi:10.1029/ 1998GL900162.

Wang, C., S. Dong, A. T. Evan, G. R. Foltz, and S.-K. Lee, 2012: Multidecadal covariability of North Atlantic sea surface temperature, African dust, Sahel rainfall, and Atlantic hurricanes. J. Climate, 25, 5404-5415, doi:10.1175/JCLI-D-11-00413.1.

Wang, Y. M., J. L. Lean, and N. R. Sheeley, 2005: Modeling the sun's magnetic field and irradiance since 1713. Astrophys. J., 625, 522-538, doi:10.1086/429689.

Williams, K. D., A. Jones, D. L. Roberts, C. A. Senior, and M. J. Woodage, 2001: The response of the climate system to the indirect effects of anthropogenic sulfate aerosol. Climate Dyn., 17, 845-856, doi:10.1007/s003820100150.

Xie, S.-P., 1999: A dynamic ocean-atmosphere model of the tropical Atlantic decadal variability. J. Climate, 12, 64-70, doi:10.1175/1520-0442-12.1.64.

Zanchettin, D., C. Timmreck, H. F. Graf, A. Rubino, S. Lorenz, K. Lohmann, K. Krüger, and J. H. Jungclaus, 2012: Bi-decadal variability excited in the coupled ocean-atmosphere system by strong tropical volcanic eruptions. Climate Dyn., 39 (1-2), 419-444, doi:10.1007/s00382-011-1167-1.

Zhang, R., 2008: Coherent surface-subsurface fingerprint of the Atlantic meridional overturning circulation. Geophys. Res. Lett., 35, L20705, doi:10.1029/2008GL035463.

, and T. L. Delworth, 2006: Impact of Atlantic multidecadal oscillations on India/Sahel rainfall and Atlantic hurricanes. Geophys. Res. Lett., 33, L17712, doi:10.1029/2006GL026267. , and Coauthors, 2013: Have aerosols caused the observed Atlantic multidecadal variability? J. Atmos. Sci., 70, 11351144, doi:10.1175/JAS-D-12-0331.1.

Zhang, Z., S. M. Kang, and I. M. Held, 2010: Sensitivity of climate change induced by the weakening of the Atlantic meridional overturning circulation to cloud feedback. J. Climate, 23, 378389, doi:10.1175/2009JCLI3118.1.

Zhou, J., and K. M. Lau, 2001: Principal modes of interannual and decadal variability of summer rainfall over South America. Int. J. Climatol., 21, 1623-1644, doi:10.1002/joc.700. 